\title{
PERANCANGAN SISTEM INFORMASI PENYELEKSIAN PENERIMA BANTUAN PERUMAHAN PADA KECAMATAN LASIOLAT KABUPATEN BELU
}

\author{
Skolastika Siba Igon ${ }^{1}$, Meliana O. Meo $^{2}$, Febrianty Bere ${ }^{3}$ \\ ${ }^{1}$ Program Studi Sistem Informasi, STIKOM Uyelindo Kupang \\ ${ }^{2,3}$ Program Studi Teknik Informatika, STIKOM Uyelindo Kupang \\ E-mail:1igon5kolastika@gmail.com,r2meliana.oktavia.g@gmail.com, ${ }^{3}$ berefebriana@gmail.com
}

\begin{abstract}
Based on the latest data from the Department of Population and Civil Registration in Belu Regency, the area of Belu Regency is 1,285 Km2, with a population of 229,561 people. From this data, Lasiolat District is one of the Districts in Belu District where there are still 299 uninhabitable houses and 1,360 housing units out of 1,659 families, with a total population of 7,171 people, an area of 13,200 Km2. Therefore, the local government through the Department of Housing and Settlements provides housing assistance to deal with problems arising from the inability of low income people. However, Lasiolat District officials still have difficulty in selecting people who are entitled to get help. Because in the selection process it is still difficult to record the large number of people manually, it takes a long time because the local government through the Housing and Settlement Office only provides as many as 100 housing units. The limited housing assistance provided, the selection process for beneficiaries who are eligible for assistance, the Department checks the data of beneficiaries through the District officials to determine citizenship, income, land ownership, type of house, building and marital status. Errors in selecting beneficiaries can result in assistance being given to recipients who do not deserve assistance. Therefore we need a system that can be used to make selections with the main objective of overcoming the problems encountered in the selection process that is currently underway. In this research, an information system for selecting housing beneficiaries will be built using the Fuzzy AHP method. The system is built based on the website. The final result expected from this research is to be able to assist the Sub-district officials in selecting housing recipients correctly and appropriately..
\end{abstract}

Keywords: recipient of housing assistance, decision support systems, housing assistance, fuzzy AHP.

\section{PENDAHULUAN}

Rumah menjadi salah satu kebutuhan dasar manusia untuk bertahan hidup. Beraneka ragam bentuk dan desain rumah diciptakan manusia dari waktu ke waktu untuk menyesuaikan diri dengan kondisi lingkungan alam tempat tinggalnya. Setiap tahun selalu terjadi peningkatan kebutuhan rumah seiring dengan pertambahan jumlah penduduk. Berdasarkan data terbaru dari Dinas Kependudukan dan Catatan Sipil Kabupaten Belu, luas wilayah Kabupaten Belu sebesar $1.285 \mathrm{Km} 2$, dengan jumlah penduduk Kabupaten Belu sebanyak 229.561 Jiwa. Dari data tersebut, Kecamatan Lasiolat merupakan salah satu Kecamatan di Kabupaten Belu yang masih terdapat rumah tidak layak huni sejumlah 299 unit dan jumlah rumah layak huni sebanyak 1.360 unit dari 1.659 Kepala Keluarga, dengan jumlah penduduk keseluruhan 7.171 jiwa, luas wilayah 13.200 Km2 (BPS, 2018).

Oleh karena itu, Pemerintah daerah melalui Dinas Perumahan dan Permukiman memberikan bantuan perumahan untuk menangani masalah yang timbul akibat ketidakmampuan masyarakat berpenghasilan rendah. Tetapi, aparat Kecamatan Lasiolat masih mengalami kesulitan dalam menyeleksi masyarakat yang berhak mendapatkan bantuan. Dikarenakan dalam melakukan penyeleksian masih kesulitan mendata masyarakat yang banyak secara manual, memerlukan waktu yang lama karena dari pemerintah daerah 
melalui Dinas Perumahan dan Permukiman hanya memberikan sebanyak 100 unit rumah bantuan. Keterbatasan bantuan perumahan yang diberikan tersebut, maka proses penyeleksian penerima yang layak mendapatkan bantuan, pihak Dinas melakukan pengecekan data penerima bantuan melalui aparat Kecamatan untuk mengetahui kewarganegaraan, penghasilan, tanah hak milik, tipe rumah, bangunan dan status perkawinannya. Kesalahan dalam penyeleksian penerima bantuan dapat mengakibatkan bantuan diberikan kepada penerima yang tidak layak mendapatkan bantuan. Untuk menghindari terjadinya kesalahan tersebut, maka dibutuhkan metode Fuzzy Analytical Hierarchy Process (FAHP). Fuzzy AHP merupakan suatu metode analisa yang dikembangkan dari AHP [12].

Beberapa penelitian mengenai Fuzzy AHP antara lain [6)] hasil pengujian dibuktikan bahwa metode FAHP memiliki tingkat kepentingan kriteria sehingga nilai bobot yang dihasilkan lebih detail sehingga metode FAHP dapat diterapkan pada penerima bantuan stimulant perumahan swadaya. Selanjutnya [9] hasil implementasi yang telah dilakukan disimpulkan dalam tabel 20 perbandingan bobot Fuzzy AHP dan AHP memberikan hasil yang berbeda sehingga metode Fuzzy merupakan metode yang tepat pada sistem pendukung keputusan dalam penyeleksian karyawan berprestasi, walaupun AHP biasa digunakan dalam menangani kriteria kualitatif dan kuantitatif namun Fuzzy AHP dianggap lebih baik dalam mendeskripsikan keputusan yang samar-samar dari AHP.

Berdasarkan penelitian-penelitian di atas maka dalam penelitan ini peneliti merancang sistem informasi penyeleksian penerima bantuan perumahan menggunakan metode Fuzzy AHP dengan studi kasus di Kecamatan Lasiolat, Kabupaten Belu.

\section{TINJAUAN PUSTAKA}

Pada penelitian terdahulu, sudah dibangun sistem dengan menggunakan metode Fuzzy AHP, antara lain [6] menggunakan menggunakan metode Fuzzy AHP untuk menentukan penerima bantuan stimulan perumahan swadaya; [3] menggunakan metode AHP untuk membantu pengambil keputusan dalam menentukan kelayakan pemberian
Kredit Usaha Rakyat dengan studi kasus di Bank Syariah Mandiri Cabang Medan; [7] menggunakan metode Fuzzy AHP untuk melakukan penyeleksian beasiswa PPA dan BBM pada Program Studi Teknologi Informasi dan Ilmu Komputer; [5] menggunakan metode AHP untuk menilai dan memberi skor penilaian sistem kredit terhadap pengetahuan pemberi pinjaman mengenai tanggung jawab sosial koheren dengan misinya atau tidak.

\subsection{Metode F-AHP}

Fuzzy Analytic Hierarchy Process (F-AHP) dapat dilihat sebagai metode analitik yang dikembangkan dari metode AHP. F-AHP merupakan penggabungan dari metode AHP dengan logika matematika Fuzzy. Perbedaannya dengan AHP adalah implementasi bobot perbandingan berpasangan di dalam matriks perbandingan, yakni diwakili oleh tiga variabel $(\mathrm{a}, \mathrm{b}, \mathrm{c})$ atau $(1, \mathrm{~m}, \mathrm{u})$ yang disebut Triangular Fuzzy Number (TFN). Hal ini berarti bobot yang ditemukan bukan satu melainkan tiga, sesuai dengan fungsi keanggotaan segitiga yang meliputi tiga bobot berurutan [4], yang dapat dilihat pada gambar 1. Fuzzy AHP mempunyai kelebihan yaitu tingkat subyektifitas dari pengambilan keputusan dapat diakomodasi. Kelebihan lain dari pendekatan Fuzzy AHP yakni memungkinkan deskripsi yang lebih akurat dari proses pengambilan keputusan [8].

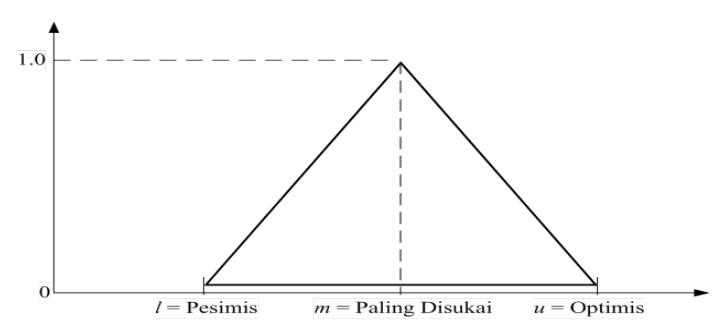

Gambar 1. Fungsi Keanggotaan Segitiga

(Rahardjo \& Sutapa, 2002)

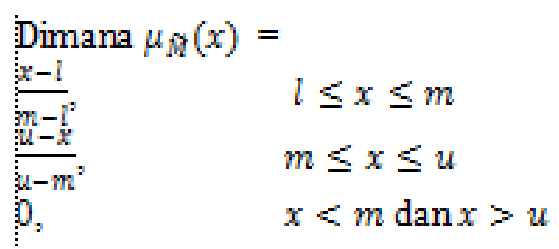

Bilangan Triangular Fuzzy Number (TFN) merupakan teori himpunan fuzzy membantu dalam pengukuran yang berhubungan dengan penelitian subjektif manusia memakai bahasa atau linguistik. Inti dari fuzzy AHP terletak 
pada perbandingan berpasangan yang digambarkan dengan skala rasio yang berhubungan dengan skala fuzzy. Bilangan TFN disimbolkan dengan M [10].

TFN disimbolkan dengan $(\mathrm{m} \quad \tilde{)}=(1, \mathrm{~m}, \mathrm{u})$, dimana $1 \leq \mathrm{m} \leq \mathrm{u}$ dan 1 adalah nilai terendah, $\mathrm{m}$ adalah nilai tengah dan $\mathrm{u}$ adalah teratas. Pendekatan TFN dalam metode AHP adalah pendekatan yang digunakan untuk meminimalisasikan ketidakpastian dalam skala AHP yang berbentuk nilai 'crisp'. Cara pendekatan yang dilakukan adalah dengan melakukan fuzzifikasi pada skala AHP sehingga diperoleh skala baru yang disebut skala fuzzy AHP. Skala penilaian yang digunakan dalam membandingkan antar kriteria dan antar sub kriteria pengukuran adalah dengan variabel linguistik, sebagai berikut dan dapat dilihat pada tabel 1 .

Tabel 1. Skala TFN dalam Variabel Linguistik

\begin{tabular}{|c|c|c|}
\hline Keterangan & $\begin{array}{c}\text { Skala } \\
\text { AHP }\end{array}$ & $\begin{array}{l}\text { Skala } \\
\text { Fuzzy }\end{array}$ \\
\hline $\begin{array}{l}\text { Kedua elemen sama } \\
\text { pentingnya }\end{array}$ & 1 & $(1,1,3)$ \\
\hline $\begin{array}{l}\text { Satu elemen sedikit lebih } \\
\text { penting dari elemen } \\
\text { lainnya }\end{array}$ & 3 & $(1,3,5)$ \\
\hline $\begin{array}{lcr}\text { Satu } & \text { elemen } & \text { lebih } \\
\text { penting } & \text { dari } & \text { elemen } \\
\text { lainnya } & & \end{array}$ & 5 & $(3,5,7)$ \\
\hline $\begin{array}{lrr}\text { Satu elemen } & \text { sangat } \\
\text { penting } & \text { dari } & \text { elemen } \\
\text { lainnya } & & \\
\end{array}$ & 7 & $(5,7,9)$ \\
\hline $\begin{array}{l}\text { Satu elemen mutlak lebih } \\
\text { penting dari elemen } \\
\text { lainnya }\end{array}$ & 9 & $(7,9,9)$ \\
\hline $\begin{array}{l}\text { Nilai-nilai antara dua } \\
\text { nilai perbandingan yang } \\
\text { berdekatan }\end{array}$ & & $\begin{array}{c}(\mathrm{x}-2), \mathrm{x}, \\
(\mathrm{x}+2)\end{array}$ \\
\hline
\end{tabular}

Sumber : [3]

Aturan-aturan operasi aritmatika Triangular Fuzzy Number yang umum digunakan. Misalkan terdapat 2 TFN yaitu $M_{1}=\left(l_{1}, m_{1}, u_{1}\right)$ dan $M_{2}=\left(l_{2}, m_{2}, u_{2}\right)$, maka operasi aritmatika Triangular Fuzzy Number (TFN) adalah sebagai berikut [2]:

$$
\begin{aligned}
& M_{1}+M_{2}=\left(l_{1}+l_{2}, m_{1}+m_{2}, u_{1}+u_{2}\right) \\
& M_{1}-M_{2}=\left(l_{1}-u_{2}, m_{1}-m_{2}, u_{1}-l_{2}\right)
\end{aligned}
$$

$$
\begin{aligned}
& M_{1} \times M_{2}=\left(l_{1}, l_{2}, m_{1}, m_{2}, u_{1}, u_{2}\right) \\
& M_{1}^{-1}=\left(1 / u_{1}, 1 / m_{1}, 1 / l_{1}\right) \\
& \frac{M_{1}}{M_{2}}=\left(1 / u_{2}, m_{1} / m_{2}, u_{1} / l_{2}\right)
\end{aligned}
$$

\section{METODOLOGI PENELITIAN}

Metode penelitian yang digunakan dalam penelitian ini adalah, sebagai berikut :

\subsection{Wawancara}

Wawancara dilakukan dengan Camat Lasiolat Kabupaten Belu selaku pengambil keputusan, serta para Pegawai dan Staff dari Kecamatan Lasiolat.

\subsection{Studi Pustaka}

Studi pustaka dilakukan untuk menelaah penelitian dan literatur yang mendukung penelitian, termasuk mencari Undang-Undang, Peraturan Pemerintah, serta Laporan dan Dokumen Kecamatan Lasiolat yang terkait dengan penyeleksian penerima bantuan perumahan.

\subsection{Metode Analisis dan Perancangan}

a. Penyusunan Hirarki

Faktor penentu keputusan kelayakan penerima bantuan perumahan pada Kecamatan Lasiolat didapatkan 9 kriteria. Struktur hirarki dari kasus ini dapat digambarkan sebagai berikut :

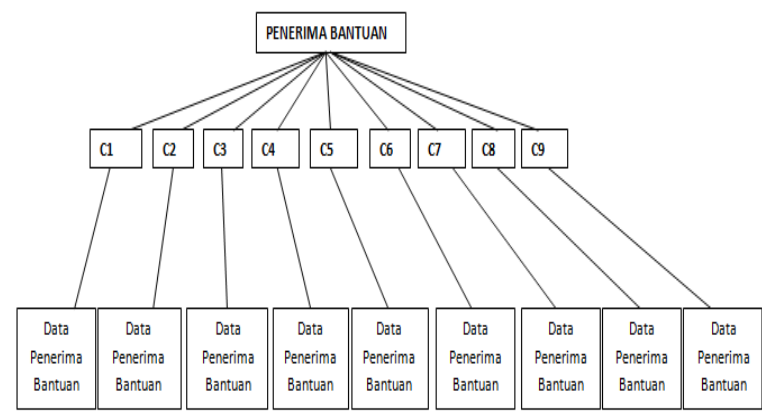

Gambar 2. Struktur hirarki penyeleksian penerima bantuan perumahan

Keterangan :

$\begin{array}{ll}\text { Kriteria } & \text { Nama Kriteria } \\ \text { C1 } & \text { Kewarganegaraan } \\ \text { C2 } & \text { Penghasilan } \\ \text { C3 } & \text { Tanah hak milik } \\ \text { C4 } & \text { Tipe rumah } \\ \text { C5 } & \text { Lantai } \\ \text { C6 } & \text { Dinding } \\ \text { C7 } & \text { Atap } \\ \text { C8 } & \text { Krangka } \\ \text { C9 } & \text { Status perkawinan }\end{array}$


b. Langkah-langkah penyeleksian dengan metode F-AHP

Langkah-langkah penyeleksian dalam penelitian ini dapat dilihat pada gambar 3 .

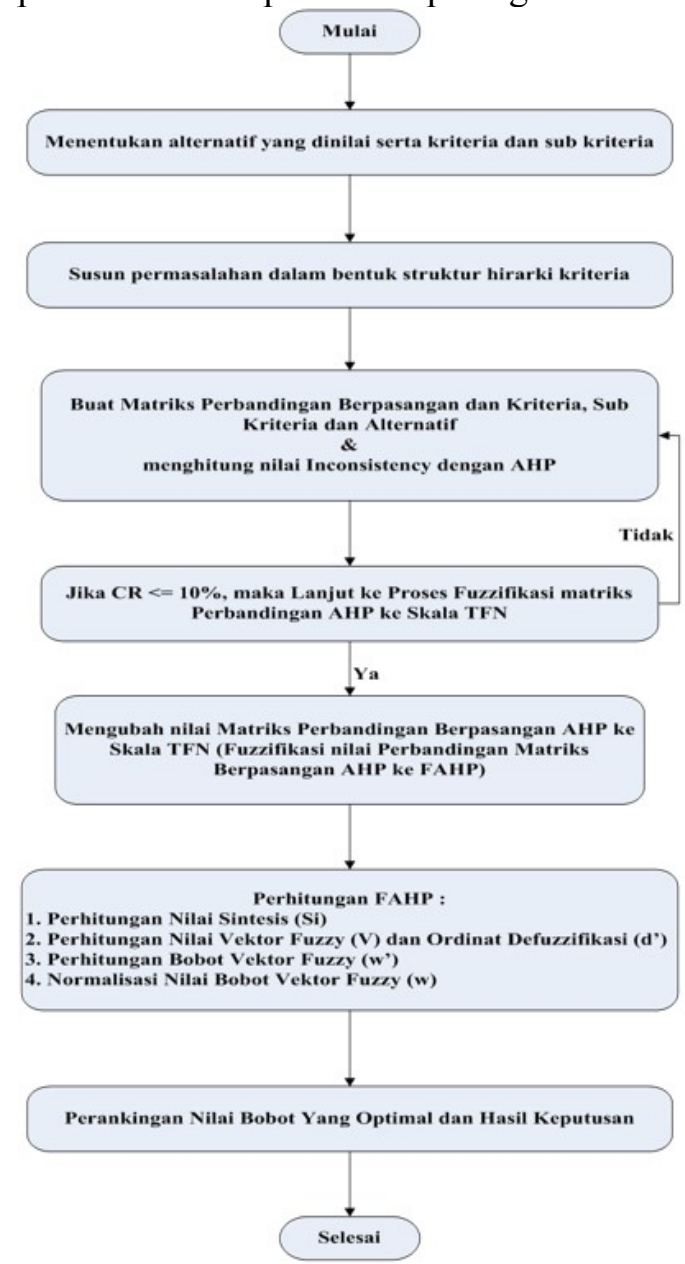

Gambar 3. Flowchart langkah-langkah penyeleksian F-AHP

Langkah-langkah Perhitungan FAHP di atas dari Chang dalam ([11]; [1]; [2]) dapat dijelaskan sebagai berikut :

a. Perhitungan nilai sintesis ( $\mathrm{Si})$

Defenisikan nilai fuzzy synthetic extent untuk i-objek seperti persamaan berikut :

$$
S_{i}=\sum_{j=1}^{m} M_{g^{i}}^{j} \times\left[\sum_{i=1}^{n} \sum_{j=1}^{m} M_{g^{i}}^{j}\right]^{-1}
$$

b. Defuzzifikasi (Anshori, 2012)

Nilai defuzzifikasi dapat diperoleh dengan persamaan sebagai berikut :

$$
D M_{i}=\frac{\left(\left(u_{i}-l_{i}\right)+\left(m_{i}-l_{i}\right)\right)}{3}+l_{i}
$$

Dimana $M_{i}=\left(l_{i}, m_{i}, u_{i}\right)$

c. Normalisasikan nilai defuzzifikasi

Nilai defuzzifikasi akan dinormalisasikan kembali dengan membagi nilai defuzzifikasi tersebut dengan nilai penjumlahan semua nilai defuzzifikasi. Hasil normlisasi defuzzifikasi merupakan nilai bobot dari masalah yang akan diselesaikan.

$$
W=\frac{D M_{i}}{\sum_{i=1}^{n} D M_{i}}
$$

\subsection{Analisis dan Perancangan Sistem \\ 3.4.1. Analisis Kebutuhan Fungsional}

Kebutuhan fungsional sistem digambarkan dalam use case pada gambar 4 sampai dengan gambar 8 .

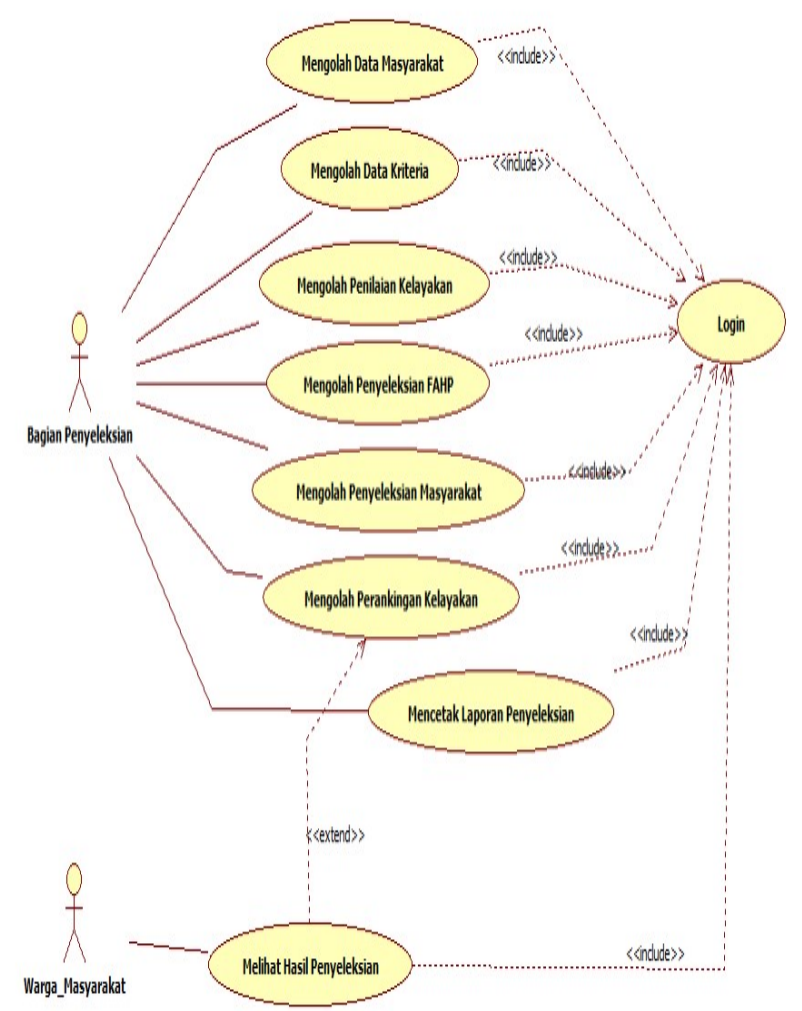

Gambar 4. Use Case Diagram Pengolahan Data Admin (Bagian Penyeleksian) dan Warga Masyarakat 


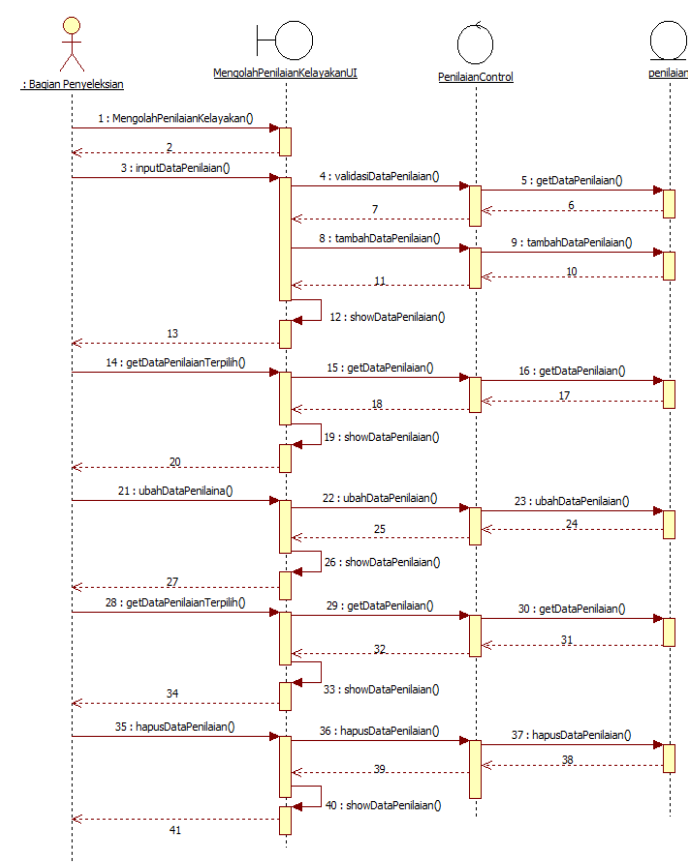

Gambar 5. Sequence Diagram Mengolah Penilaian Kelayakan

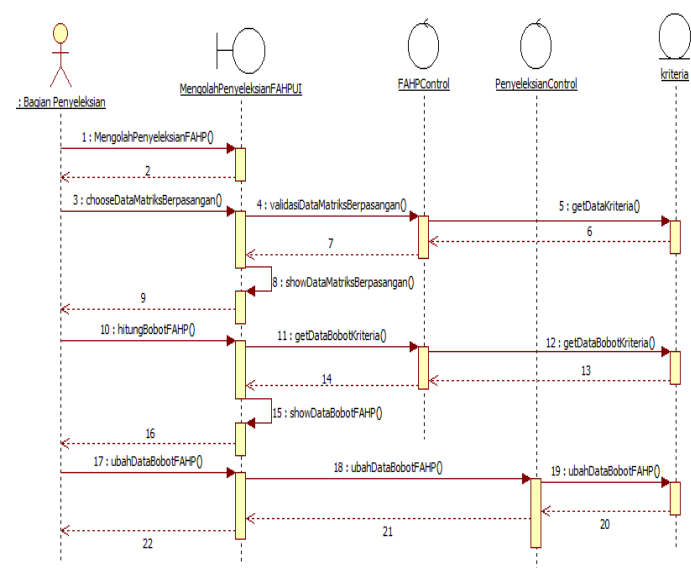

Gambar 6. Sequence Diagram Mengolah Penyeleksian FAHP

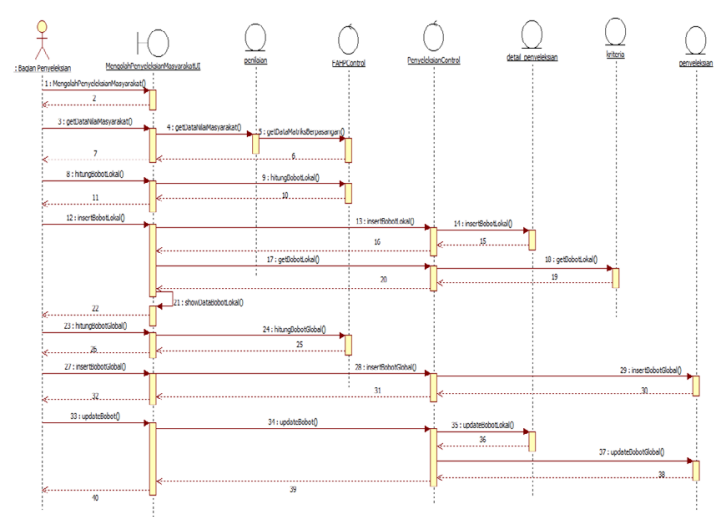

Gambar 7. Sequence Diagram Mengolah Penyeleksian Alternatif (Masyarakat)

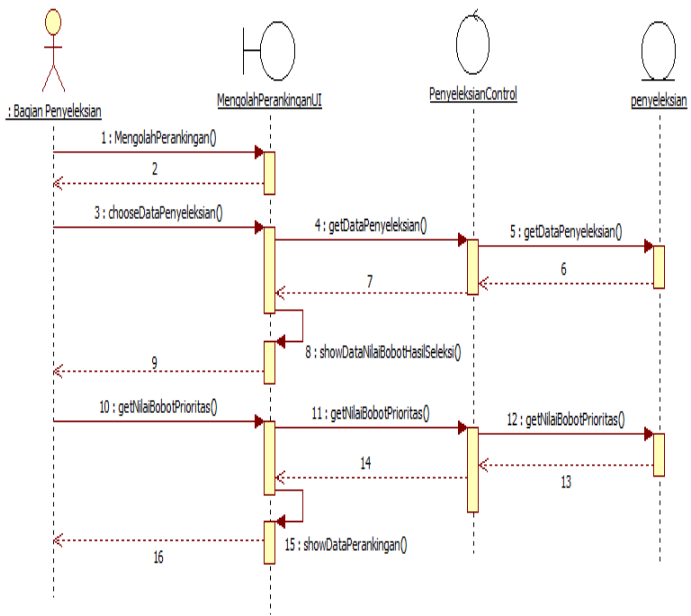

Gambar 8. Sequence Diagram Mengolah Perankingan Kelayakan

\subsubsection{Analisis Kebutuhan Data}

Kebutuhan data perangkat lunak sistem penyeleksian penerima bantuan perumahan dituangkan dalam Class Diagram Diagram pada gambar 9 berikut :

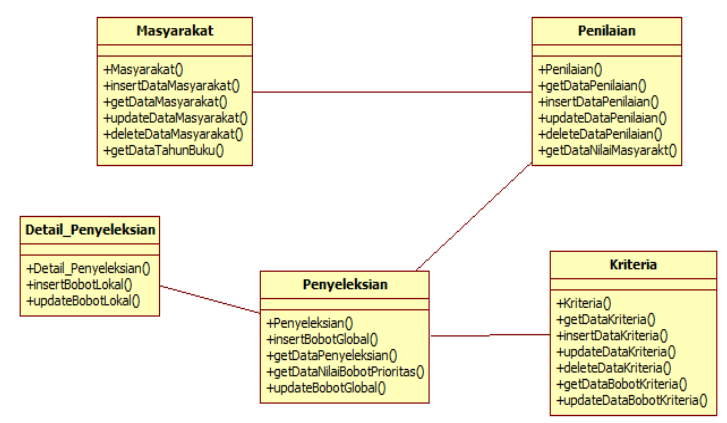

Gambar 9. Class Diagram (ERD)

\section{SIMPULAN}

Proses analisis dan perancangan perangkat lunak sistem informasi penyeleksian ini dapat digunakan sebagai panduan untuk implementasi sistem informasi penyeleksian penerima bantuan perumahan.

Sistem penyeleksian penerima bantuan perumahan menggunakan metode F-AHP ini menghasilkan keputusan yang lebihi obyektif berupa daftar peranckingan kelayakan warga masyarakat untuk menerima bantuan perumahan.

Dengan memanfaatkan teknologi pemrograman dan database yang ada, proses penyeleksian penerima bantuan perumahan dapat dilakukan dengan cepat karena tidak memerlukan komputasi secara manual, dengan sistem terkomputerisasi maka penyeleksian 
penerima bantuan perumahan pada kecamatan Lasiolat dapat dilakukan dengan cepat dan hasilnya dapat diketahui langsung oleh warga.

\section{DAFTAR PUSTAKA}

[1] Abdi, M., Alireza \& Fathi, M. R., 2012. Applying Fuzzy Analytic Hierarchy Process for Ranking of Financial Strategies. New York Science Journal, 5(6).

[2] Anshori, Y., 2012. Pendekatan Triangular Fuzzy Number dalam Metode Analytic Hierarchy Process. Jurnal Ilmiah Foristek, Volume 2, No. 1.

[3] Azwany, F., 2010. Sistem Pendukung Keputusan Pemberian Kredit Usaha Rakyat Pada Bank Syariah Mandiri Cabang Medan Menggunakan Metode Analytical Hierarchy Process (AHP), Medan: Program Studi Ilmu Komputer, Fakultas Matematika dan Ilmu Pengetahuan ALam, Universitas Sumatera Utara.

[4] Bire, C. E., Ernawati \& Dwiandiyanta, B. Y., 2012. Perancangan Sistem Pendukung Keputusan Untuk Kenaikan Jabatan Pegawai Menggunakan Fuzzy Analytic Hierarchy Process. Semarang, Seminar Nasional Ilmu Komputer, Universitas Diponegoro.

[5] Gutierrez-Nieto, B., Serrano-Cinca, C. \& Camon-Cala, J., 2011. A Credit Score System For Socially Respincible Lending. Centre Emile Bernheim, Research Institute in Management Sciences, Volume 11, p. 028.

[6] Hadi, Fathul; Andi, Farmadi; Dwi, Kartini. 2016. Fuzzy Analytical Hierarchy Process (FAHP) pada Penerima Bantuan Stimulan Perumahan Swadaya. Jurnal Ilmiah KLIK, Volume 3, No. 1.

[7] Iskandar, F. M.,. 2013. Sistem Pendukung Keputusan Seleksi Beasiswa PPA dan BBM Menggunakan Metode Fuzzy AHP. Malang: Universitas Brawijaya. Program Studi Teknik Informatika.

[8] Kabir, G. \& Hasin, A. A., 2011. Comparative Analysis of AHP and Fuzzy AHP Models for Multi Criteria Inventory Classification. International Journal of Fuzzy Logic Systems (IJFLS), Volume 1, No. 1.
[9] Norhikmah; Rumini; Henderi. 2013. Metode Fuzzy AHP dan AHP dalam Penerapan Sistem Pendukung Keputusan. Yogyakarta: Seminar Nasional Teknologi Informasi dan Multimedia.

[10] Shega, H. N. H., Rahmawati, R. \& Yasin, H., 2012. Penentuan Faktor Prioritas Mahasiswa Dalam Memilih Telepon Seluler Merk Blackberry Dengan Fuzzy AHP. Semarang, Seminar Nasional Ilmu Komputer, Universitas Diponegoro.

[11] Turgut, B. T. et al., 2011. A Fuzzy AHP Based Decision Support System for Disaster Center Location Selection and A Case Study for Istanbul. Disaster Prevention and Management, Volume 20, No. 5, pp. 499-520.

[12] Wahyuni, Sri. 2012. Sistem Pendukung Keputusan Model Fuzzy AHP dalam Pemilihan Kualitas Perdagangan Batu Mulia. IJCCS, Volume 6, No. 1. 